\title{
PENANAMAN PENDIDIKAN AGAMA DI TAMAN KANAK_KANAK
}

\author{
Samsiah
}

\section{Dosen PGPAUD FIP UNG}

\begin{abstract}
Abstrak
Penanaman Pendidikan agama pertama dan utama berasal dari keluarga, orang tua ketika anaknya masuk usia Taman Kanak-Kanak dapat bekerjasama dengan Taman Kanak kanak dalam penanaman pendidikan agama, hal ini dikarenakan orang tua menyadari penanaman pendidikan agama sejak dini jauh lebih baik dari sesudah anak dewasa. Penelitian ini dilakukan di Taman Kanak-Kanak Qurratu a'yun yang di dalam kegiatan belajarnya terdapat muatan penanaman pendidikan agama. penelitian ini menggunakan penelitian kualitatif, data yang terkumpul dan analisisnya lebih bersifat kualitatif. Peneltian ini bertujuan untuk memberikan informasi bagaimana penanaman pendidikan agama di Taman Kanak-Kanak Qurratu a'yun. Hasil penelitian menunjukkan bahwa penanaman pendidikan agama di Taman Kanak-Kanak Qurratu a'yun yaitu melaksanakan kegiatan pembelajaran dengan muatan agama yaitu mengajarkan : a) Tauhid, b) Hafalan Surah, c) Hafalan hadist, d) Hafalan Bacaan sholat, e) Hafalan Doa harian, f) Adab Islami, g) Bahasa arab dan bahasa lnggris, dan h) Kisah Teladan.
\end{abstract}

Kata Kunci : Pendidikan Agama, Taman Kanak-Kanak

\section{A. PENDAHULUAN}

Undang-undang nomor 20 tahun 2003 tentang Standar Pendidikan Nasional pasal 1 ayat 14 Pendidikan Anak Usia Dini adalah suatu upaya pembinaan yang ditujukan kepada anak sejak lahir sampai dengan usia enam tahun yang dilakukan melalui pemberian rangsangan pendidikan untuk membantu pertumbuhan dan perkembangan jasmani dan rohani agar anak memiliki kesiapan dalam memasuki pendidikan lebih lanjut.

Anak Usia Dini merupakan anak yang membutuhkan stimulasi agar dapat berkembang secara optimal dan pada masa ini anak masuk pada fase usia golden age. Patmonodewo (2003:43) mengatakan batasan yang digunakan oleh The National Association for The Education of Young Children (NAEYC) dan para ahli pada umumnya sebagai berikut : a) yang dimaksudkan dengan "Early Chilhood" (anak masa awal) adalah anak yang sejak lahir sampai dengan usia delapan tahun. Hal tersebut merupakan pengertian yang baku yang dipergunakan oleh NAEYC. Batasan ini sering dipergunakan untuk merujuk anak yang belum mencapai usia sekolah dan masyarakat menggunakannya bagi berbagai tipe prasekolah (preschool), b) early 
childhood setting (tatanan anak masa awal) menunjukkan pelayanan untuk anak sejak lahir sampai dengan delapan tahun di suatu pusat penyelenggaraan, rumah, atau institusi, seperti Kinder Garten, Sekolah Dasar dan program rekreasi yang menggunakan sebagian waktu atau penuh waktu. c) Early Childhood Education (pendidikan awal masa anak) terdiri dari pelayanan yang diberikan dalam tatanan awal masa anak. Biasanya oleh para pendidik anak usia dini (young children) digunakan istilah early childhood (anak masa awal) dianggap sama atau sinonim.

$$
\text { Pada usia dini Penanaman }
$$

Pendidikan agama merupakan tugas utama orang tua bagi anak-anaknya, Menurut Mohamad Surya (2001:27) Agama (Islam) dengan tegas menyatakan bahwa hakikat anak adalah : a) perhiasan kehidupan, b) perisai dari api neraka bagi kedua orangtyanya, c) tulang punggung orangtua, d) karunia Allah SWT, e) pembawa orangtua ke syurga dan f) penyambung amal ibadah. Masih menurut Mohamad Surya (2001:96) inti dari pendidikan dalam keluarga ialah pendidikan agama, inti dari pendidikan agama ialah pendidikan keimanan, dan inti pendidikan keimanan ialah pendidikan ketauhidan. Agar pendidikan dapat berlangsung dengan baik, maka ada sejumlah tonggak yang harus diperhatikan yaitu : a) Pendidikan agama sebagai inti dari pendidikan secara keseluruhan untuk membangun landasan bagi pembentukan kualitas mnausia secarah utuh; b) kasih sayang yang tulus dari orang tua dalam berbagai aktivitas pendidikan; c) memperhatikan perkembangan dan kebutuhan anak; d) menciptakan situasi kondusif, bagi berlangsungnya pendidikan yang efektif; e) pembentukan kebiasaan,untuk mewujudkan perilakuperilaku yang baik; f) orang tua hendaknya menjadi sumber keteladanan bagi anak; g) memberikan motivasi dan bimbingan bagi anak; h) terbinanya komunikasi yang efektif antara orang tua dengan anak dan anggota keluarga lainnya.

Menurut Farmawi M. Farmawi dkk (2001:23-24) orang tua harus membiasakan anaknya menjadi pendengar yang baik, mengajarinya kapan harus berbicara, tidak boleh memotong pembicaraan, tidak boleh tergesa-gesa menanggapi pembicaraan orang lain, hendaklah mereka menunggu sampai orang selesai berbicara meskipun berbeda pandangan, dan hendaklah mereka menghormati pandangan orang lain selama dalam masalah-masalah ijtihadiyah. Orang tua juga harus melatih anak - anak meluruskan pikiran dengan cara yang halus, 
merapikan tulisan, dan memperbaiki ucapan . Hal ini dilakukan dengan harapan kebiasaan-kebiasaan buruk yang banyak dijumpai pada orang dewasa dapat dihindari sejak kecil karena kebiasaan buruk merupakan hal serius yang mengkhawatirkan dan membahayakan.

Taman Kanak-kanak dapat membantu orang tua dan bekerja sama dalam penanaman pendidikan agama, orang tua menyadari penanaman pendidikan agama sejak dini jauh lebih baik dari sesudah anak dewasa. Dalam penelitian ini peneliti meneliti di Taman Kanak-Kanak Qurratu a'yun kota Gorontalo yang merupakan Taman Kanak-Kanak dalam pembelajarannya terdapat muatan pendidikan agama. Berdasarkan uraian di atas maka rumusan masalah dalam penelitian ini adalah bagaimana Penanaman Pendidikan Agama di Taman Kanak-Kanak Qurratu a'yun, peneltian ini bertujuan untuk memberikan informasi bagaimana Penanaman Pendidikan Agama di Taman Kanak-Kanak Qurratu a’yun .

\section{B. METODE PENELITIAN}

Metode Penelitian yang digunakan dalam penelitian ini menggunakan metode kualitatif menurut Sugiono (2011:8) metode penelitian kualitatif sering di sebut metode penelitian naturalistik karena penelitiannya dilakukan pada kondisi yang alamiah (natural setting); di sebut juga sebagai metode etnographi, karena pada awalnya metode ini lebih banyak digunakan untuk penelitian bidang antropologi budaya; disebut sebagai metode kualitatif, karena data yang terkumpul dan analisisnya lebih bersifat kualitatif.

\section{HASIL PENELITIAN DAN PEMBAHASAN}

Anak adalah anugerah dari Allah yang harus di bimbing dan di rawat sesuai dengan fase perkembangan anak. Layanan Pendidikan anak Usia Dini memberikan kontribusi dalam menstimulasi perkembangan anak, menurut Soegeng Santoso (2004:27) Fungsi dari ruang lingkup PAUD terwujudnya berbagai program yang memberikan layanan bagi kebutuhan anak usia dini, pada anak usia 8 tahun agar dapat mengembangkan potensi dan kemampuan intelektual, emosional, spiritual, moral dan fisik secara optimal, sehingga menghasilkan generasi yang unggul dan mampu bersaing secara global. Oleh karena itu secara rinci PAUD dapat berfungsi untuk : a) memberikan kesempatan yang seluasluasnya kepada anak Indonesia untuk mengikuti pendidikan anak usia dini sesuai 
dengan potensi yang dimilikinya, bahkan secara tidak langsung sejak anak masih dalam kandungan, b) membantu dan memfasilitasi pengembangan potensi anak bangsa secara utuh di lingkungan keluarga, masyarakat (Kelompok Bermain, Tempat Penitipan anak) c) membantu memperbaiki mutu dan relevansi pendidikan anak usia dini setara dengan mutu pendidikan dari Negara lain, d) memberdayakan peran serta masyarakat dalam penyelenggaraan pendidikan anak usia dini berdasarkan prinsip otonom daerah dalam konteks Negara Kesatuan Republik Indonesia, e) setiap instansi pemerintah, swasta, LSM, yayasan atau lembaga pendidikan yang lain boleh melaksanakan program PAUD dengan mengacu pada pedoman dari Direktorat PADU Depdiknas.

Menurut Yuliani Nurani (2009:4243) Tujuan PAUD yang ingin dicapai adalah untuk mengembangkan pengetahuan dan pemahaman orang tua dan guru serta pihak-pihak yang terkait dengan pendidikan dan perkembangan anak usia dini. Secara khusus tujuan yang ingin dicapai, adalah :a) Dapat mengidentifikasi perkembangan fisiologi anak usia dini dan mengaplikasikan hasil identifikasi tersebut dalam pengembangan fisiologis yang bersangkutan b) Dapat memahami perkembangan kreativitas anak usia dini dan usaha-usaha yang terkait dengan pengembangannya. c) Dapat memahami kecerdasan jamak dan kaitannya dengan perkembangan anak usia dini d) Dapat memahami arti bermain bagi perkembangan anak usia dini. e) Dapat memahami pendekatan pembelajaran dan aplikasinya bagi pengembangan anak usia kanak-kanak.

Adapun tujuan pendidikan anak usia dini secara umum adalah mengembangkan berbagai potensi anak sejak dini sebagai persiapan untuk hidup dan dapat menyesuaikan diri dengan lingkungannya. Secara khusus kegiatan pendidikan bertujuan agar : a) Anak mampu melakukan ibadah, mengenal dan percaya akan ciptaan Tuhan dan mencintai sesama. Contoh: pendidikan mengenalkan kepada anak didik bahwa Allah SWT menciptakan berbagai makhluk selain manusia, seperti binatang, tumbuhan, dan sebagainya yang semua itu harus kita sayangi. b) Anak mampu mengelola keterampilan tubuh termasuk gerakan-gerakan yang mengontrol gerakan tubuh, gerakan halus dan gerakan kasar, serta menerima rangsangan sensorik (panca indera). Contoh: menari, bermain bola, menulis ataupun mewarnai. c) Anak mampu menggunakan bahasa untuk pemahaman bahasa pasif dan dapat berkomunikasi secara 
efektif yang bermanfaat untuk berpikir dan belajar. Contoh: ketika sudah melakukan pembahasan tema, diberikan kepada anak didik untuk bertanya atau menjawab isi tema yang telah dibahas. d) Anak mampu berpikir logis, kritis, memberikan alasan, memecahkan masalah dan menemukan hubungan sebab akibat. Contoh: mencari pasangan gambar yang berkaitan dengan sebab akibat, lalu anak akan berusaha memecahkan masalah dan memberikan alasan tersebut. e) Anak mampu mengenal lingkungan alam, lingkungan sosial, peranan masyarakat dan menghargai keseragaman sosial dan budaya serta mampu mengembangkan konsep diri, sikap positif terhadap belajar, control diri dan rasa memiliki. f) Anak memiliki kepekaan terhadap irama, nada, birama, berbagai bunyi, bertepuk tangan, serta menghargai hasil karya yang kreatif. Contoh: anak yang senang dan menyukai dengan musik, saat mendengar lagu maka akan segera mengikutinya, ataupun ketika diminta melanjutkan syair kedua hingga selesai, maka anak mampu melakukannya.

Anak-anak tumbuh dan berkembang sesuai dengan usianya, menurut Eti Nurhayati "Memahami Tumbuh Kembang Anak usia Dini Perspektif Psikologi perkembangan" http://download.portalgaruda.org/article.php ?article $=447258 \& \mathrm{val}=9466 \&$ title $=\mathrm{MEMAH}$ AMI\%20TUMBUH\%20KEMBANG\%20A NAK\%20USIA\%20DINI\%20(Perspektif\%2 0Psikologi\%20Perkembangan) untuk memahami tumbuh kembang anak prasekolah dalam pandangan 1slam, dapat menukil salah satu hadist nabi SAW "suruhlah anak-anakmu shalat saat mereka berumur tujuh tahun, dan pukullah (tidaklah lebih tegas) saat mereka berumur sepuluh tahun dan pisahkanlah tidur darimu" (Abu Daud, tanpa tahun: 115). Berdasarkan hadits tersebut, bagi anak-anak prasekolah yang belum mencapai usia 7.0 harus mulai diajarkan tatacara dan membiasakan shalat wajib oleh orang tua dan gurunya. Membiasakan anak untuk melaksanakan shalat harus menjadi perhatian orang tua, disamping memberi contoh shalat yang benar, karena anak prasekolah banyak meniru tindakan orang dewasa.

Di samping pendidikan shalat untuk anak prasekolah, mereka juga harus mulai ditanamkan pendidikan keimanan dan hokum islam mengikuti tahapan sebagai berikut: Tahap pertama, pendengarkan dan kalimat pertama kepada anak "Lailaaha illa Allah" sebagaimana sabda Nabi SAW: "perdengarkan kalimat awal pertama kepada anak-anakmu lafadz laa ilaaha illa allah" 
(H.R. hakim dari Ibnu Abbas RA). tahap

kedua, kenalkan dengan hukum-hukum halal dan haram, sebagaimana sabda Nabi SAW: “ajarkan anak-anakmu untuk melaksanakan ketaatan kepada Allah, ketakutan berbuat dosa, melaksanakan perintah Allah, menjauhi larangan Allah. Yang demikian itu sebagai tameng bagimu meski kamu di neraka" (H.R. Ibnu Jarir dan Ibnu Mundzir dari Ibnu Abbas RA). Tahap ketiga, perintahkan anakmu agar beribadah (shalat) saat mereka berusia tujuh tahun, sebagaimana sabda Nabi SAW : "suruhlah anak-anakmu shalat saat mereka berusia tujuh tahun, dan pukullah (tidaklah lebih tegas) saat mereka berusai sepuluh tahun dan pisahkan tidur darimu, didiklah berpuasa saat mereka telah kuat, ajaklah berhaji jika orang tuanya mampu" (H.R. Hakim \& Abu Daud dari Ibnu Umar \& Ibnu Ash). Tahun keempat, didiklah agar mencintai Rasulullah dan keluarganya, serta belajar al-Qur'an, sebagaimana sabda Nabi SAW : " didiklah anak-anakmu mencakup tiga perkara : mencintai Nabimu (Muhammad SAW), mencintai keluarga nabi, dan membaca Al-Qur'an karena sesungguhnya Al-Qur'an itu dalam genggaman arsy' Allah pada hari ketika tidak ada lagi perlindungan kecuali lindungan Allah, para Anbiya dan Ashfiya"
(H.R. Thabrani dari Ali KW). (Abdullah Nashih Ulwan, tanpa tahun: 148-150). Pendidikan agama kepada anak harus dimulai sejak anak mengenal dunia, bahkan saat masih dalam kandungan. Pendidikan di RA hendaknya tidak latah dan hanya berjalan mengikuti pendidikan sekuler yang tidak menekankan pendidikan agama. Perkembangan psikologis yang telah dipaparkan diatas dapat menjadi acuan metodologis untuk mendidik anak-anak prasekolah, sedangkan kontennya dapat memformulasikan sesuai referensi yang bersumber dari Al-Qur'an dan al-sunnah.

Menurut Muhammad Fahd AtsTsuwaini (2008:32) Anak pada masa kanakkanak (2-10 tahun) dan remaja (10-18 tahun) mempunyai sifat cerdas dan memahami orang tuanya dengan baik, bahkan beberapa anak memahami makna gerakan dan isyarat, demikian juga mereka memahami nada suara karena kedekatan mereka dan pemahaman mereka terhadap orangtua. Oleh karena itu, pemahaman ini kadang membuat anak mencari perhatian ayah atau ibu dengan cara sengaja menolak perintah dengan cara langsung atau tidak hanya untuk mendapat dukungan dan perhatian bahwa dia adalah anak mereka.

Menurut Akh Muwafik Saleh (2011:84) Ridha orang tua adalah cara untuk mengetuk 
pintu rahmat Allah SWT, walau sesungguhnya pintu rahmat itu selalu terbuka untuk hamba-Nya.

Proses kegiatan pembelajaran anakanak harus diperhatikan cara anak belajar menurut Partin (2010:10-11) dalam proses pembelajaran, orang tua, dan pendidik juga mesti memperhatikan bagaimana cara anak belajar yang ternyata juga mengalami perkembangan dan perubahan seiring bertambahnya usia. Berikut ini adalah cara belajar anak seiring bertambahnya usia (Hibana, 2002) pertama, usia 0-1 tahun anak belajar menggunakan panca indera yang sedang terus disempurnakan meliputi penglihatan, pendengaran, penciuman peraba dan perasa. Untuk mengenal bendabenda anak ingin menyentuh apa yang dilihatnya dan memasukkannya ke dalam mulut, kedua usia 2-3 tahun anak belajar dengan cara meniru objek-objek bergerak disekitarnya baik yang ia lihat atau pun ia dengar. Perkembangan bahasa juga berkembang dengan meniru orang lain berkata-kata. Semakin banyak pengaruh mengajari anak berkata-kata, semakin banyak pula ia belajar, ketiga usia 4-6 tahun meski belum fasih, kemampuan bahasa anak sudah baik dan dapat digunakan untuk komunikasi. saat inilah anak belajar dengan cara bertanya kepada kepada orang yang lebih dewasa tentang apa saja yang menarik minatnya, di usia ini umumnya anak telah dapat membaca tulisan. Informasi yang ia dapatkan melalui inderanya semakin bertambah. Anak mulai dapat belajar sendiri dengan membaca buku.

Lampiran 1 Peraturan Menteri Pendidikan dan Kebudayaan Republik Indonesia nomor 137 tahun 2014 tentang Standar Nasional Pendidikan Anak Usia Dini, Standar isi tentang Tingkat Pencapaian Perkembangan Anak dalam Lingkup Perkembangan Nilai Agama Moral kelompok usia 4-5 tahun dan 5-6 tahun yaitu :

\begin{tabular}{|c|c|}
\hline Lingkup & Tingkat Pencapaian P \\
\hline $\begin{array}{c}\text { Perkembanga } \\
\mathbf{n}\end{array}$ & Usia 4-5 tahun \\
\hline $\begin{array}{l}\text { Nilai Agama } \\
\text { Moral }\end{array}$ & $\begin{array}{l}\text { 1. Mengetahui agama yang } \\
\text { dianutnya } \\
\text { 2. Meniru gerakan } \\
\text { beribadah dengan urutan } \\
\text { yang benar } \\
\text { 3. Mengucapkan doa sebelu } \\
\text { m dan/atau sesudah } \\
\text { melakukan sesuatu } \\
\text { 4. Mengenal perilaku } \\
\text { baik/sopan dan buruk } \\
\text { 5. Membiasakan diri } \\
\text { berperilaku baik } \\
\text { 6. Mengucapkan salam dan } \\
\text { membalas salam }\end{array}$ \\
\hline
\end{tabular}


Taman Kanak-Kanak Qurratu a’yun melaksanakan kegiatan pembelajaran dengan muatan agama seperti mengajarkan: a) Tauhid, b) Hafalan Surah, c) Hafalan hadist, d) Hafalan Bacaan sholat, e) Hafalan Doa harian, f) Adab Islami, g) Bahasa arab dan bahasa lnggris, dan h) Kisah Teladan. Berdasarkan hasil observasi dan wawancara dengan Kepala sekolah dan guru kelompok B kegiatan agama ini dilakukan diawal pembelajaran dengan cara muroja'ah (mengulang kembali pelajaran) setiap hari yaitu : hafalan surah, hafalan hadist, hafalan bacaan sholat, hafalan doa harian.

Kegiatan Muroja'ah untuk adab islami, bahasa arab dan bahasa Inggris, serta kisah teladan dimuroja'ah sesuai tema. Kegiatan muroja'ah bukan hanya di Taman Kanak-Kanak diharapkan di rumah orang tua memuroja'ah kembali apa yang telah dimuroja'ah di Taman Kanak-Kanak. Tujuan Memuroja'ah agar anak-anak dapat hafal dan memahami apa yang sudah dipelajari. Misalnya ketika ada anak yang lupa minum sambil berdiri lalu diingatkan bagaimana adab islami makan dan minum.

Berdasarkan Buku Panduan Pembelajaran TK tahun pelajaran 2017/2018 TK/KB Qurratu A'yun kegiatan pembelajaran dengan muatan agama dalam tema binatang yaitu : a) Tauhid : mengenal enam rukun iman

b) Hafalan Surah : TK B : surah Al-Kautsar dan surah Al-Ma'un

c) Hafalan hadist : Hadist larangan menyiksa Binatang dan Hadist tentang Akhlak

d) Hafalan Bacaan sholat : Doa I'tidal dan Doa sujud

e) Hafalan Doa harian : Doa naik kenderaan

f) Adab Islami : adab ketika naik kendaraan : membaca doa naik kendaraan : membaca doa naik kendaraan, mendahulukan kaki kanan ketika naik kendaraan, banyak berzikir (mengingat Allah) ketika diperjalanan, mematuhi lalulintas, bersyukur kepada allah ketika sampai di tempat yang di tuju dan mendahulukan kaki kiri ketika turun dari kendaraan.

g) Bahasa arab dan bahasa lnggris:

\begin{tabular}{|l|l|l|}
\hline $\begin{array}{l}\text { Kata } \\
\text { Indon } \\
\text { esia }\end{array}$ & $\begin{array}{l}\text { Bahasa } \\
\text { Arab }\end{array}$ & $\begin{array}{l}\text { Baha } \\
\text { sa } \\
\text { Inggr } \\
\text { is }\end{array}$ \\
\hline Ayam & Dikun & $\begin{array}{l}\text { Chic } \\
\text { ken }\end{array}$ \\
\hline $\begin{array}{l}\text { Kucin } \\
\text { g }\end{array}$ & Qittun & Cat \\
\hline Sapi & Baqaratun & Cow \\
\hline Ikan & Samakun & Fish \\
\hline $\begin{array}{l}\text { Anjin } \\
\text { g }\end{array}$ & Kalbun & Dog \\
\hline Onta & Jamalun & $\begin{array}{l}\text { Came } \\
1\end{array}$ \\
\hline Kamb & Ghonamun & Goat \\
\hline
\end{tabular}




\begin{tabular}{|l|l|l|}
\hline ing & & \\
\hline $\begin{array}{l}\text { Kelin } \\
\text { ci }\end{array}$ & Amabun & $\begin{array}{l}\text { Rabb } \\
\text { it }\end{array}$ \\
\hline Gajah & Fiilun & $\begin{array}{l}\text { Eleph } \\
\text { ant }\end{array}$ \\
\hline $\begin{array}{l}\text { Burun } \\
\text { g }\end{array}$ & $\begin{array}{l}\text { Thoirun/ya } \\
\text { mamah }\end{array}$ & Bird \\
\hline
\end{tabular}

h) Kisah Teladan : kisah nabi Sulaiman 'Alaihisalam

Beliau adalah putra dari nabi Daud, Allah memberi mu'jizat /keutamaan kepada nabi Sulaiman yakni beliau dapat mengerti dan berbicara dengan bahasa binatang sehingga seluruh binatang yang hidup dimasanya semuanya tunduk dan hormat kepada nabi sulaeman begitu pun parajin patut pada perinta nabi sulaeman. Meskipun beliau memiliki banyak keutamaan tidak membuat beliau sombong karena semua itu atas kehendak allah.

Salah satu kisahnya...ketika nabi sulaeman melakukan perjalanan kekota asgalan ditengah jalan beliau bertemu dengan serombongan semut yang berbicara kepada teman-temannya sesama semut' hai semutsemut,masuklah kalian semuakedalam sarang agar kalian tidak terinjak oleh rombongan pasukan nabi sulaeman'...nabi pun tersenyum mendengar percakapan si semut tersebut dan memerintahkan pasukannya untuk berhenti dan membiarkan para semut untuk masuk kedalam sarangnya...subhanallah

Nasyid : Binatang kecil, ini kura-kura, pak tani punya kandang dan lain-lain (Nasyid di sesuaikan dengan tema)

\section{KESIMPULAN}

Hasil penelitian ini menyimpulkan bahwa Penanaman Pendidikan Agama di Taman Kanak-Kanak Qurratu a'yun melaksanakan kegiatan pembelajaran dengan muatan agama yaitu mengajarkan : a) Tauhid, b) Hafalan Surah, c) Hafalan hadist, d) Hafalan Bacaan sholat, e) Hafalan Doa harian, f) Adab Islami, g) Bahasa arab dan bahasa lnggris, dan h) Kisah Teladan.

\section{REFERENSI}

Ats-Tsuwaini Fahd Muhammad, 2008. Seni Mendidik Anak tanpa Kekerasan. Menjadi orang tua yang mencintai anak, Solo : Abyan

Buku Panduan Pembelajaran TK tahun pelajaran 2017/2018 TK/KB Qurratu A'yun

Farmawi M. Farmawi, 2001, Memanfaatkan waktu anak bagaimana caranya?,Jakarta : Gema Insani Press Nurani Yuliani, 2009. Konsep Dasar PAUD, Jakarta : Indeks 
Partin, 2010. Pengantar Pendidikan Anak usia Dini, Yogyakarta : Penerbit Grafindo Litera Media

Patmonodewo Soemiarti, 2003. Pendidikan Anak Prasekolah, Jakarta : Penerbit Rieneka Cipta

Peraturan Menteri Pendidikan dan Kebudayaan Republik Indonesia nomor 137 tahun 2014 tentang Standar Nasional Pendidikan Anak Usia Dini

Saleh Muwafik Akh, 2011. Belajar dengan hati nurani, Jakarta : Erlangga

Santoso Soegeng, 2004. Pendidikan Anak Usia Dini, Jakarta : Citra Pendidikan

Sugiyono, 2011. Metode Penelitian Kuantitatif Kualitatif dan R \& D, Bandung : Penerbit Alfabeta

Surya Mohamad, 2001, Bina Keluarga, Semarang : Aneka Ilmu

Undang-Undang nomor 20 tahun 2003 tentang Sistem Pendidikan Nasional http://download.portalgaruda.org/article.php ?article $=447258 \&$ val $=9466 \&$ title $=$ MEMAH AMI\%20TUMBUH\%20KEMBANG\%20A NAK\%20USIA\%20DINI\%20(Perspektif\%2 OPsikologi\%20Perkembangan) 